\title{
Shock-induced fighting in septal-lesioned rats '
}

ALLAN B. WETZEL ${ }^{2}$, ROBERT L. CONNER AND SEYMOUR LEVINE 3 STANFORD UNIVERSITY SCHOOL OF MEDICINE

Emotionality ratings of rats with bilateral lesions in the septal area were elevated two days and 30 days after lesion placement. At approximately 85 days after lesioning, pairs of septal animals exhibited significantly more fighting in response to electric shock stimulation than control animals even though at this time their emotionality ratings did not differ from those of control animals.

Shortly after placement of bilateral lesions in the septal area of the brain, rats become difficult to capture and handle, frequently and voraciously attack other objects and organisms in the immediate vicinity (King, 1958), and show exaggerated startle responses to a sudden acoustical stimulus (Brady \& Nauta, 1953). These and similar observations have been cited as behavioral evidence for the view that septal animals are "hyperemotional" (cf., King, 1958). The hyperemotionality is apparently transitory. After a short period of time the reactions of septal animals in these same standardized testing situations are not markedly different from those of nonoperated control animals (Brady \& Nauta, 1955; Yutzey, Meyer, \& Meyer, 1964).

On the other hand, however, there is evidence of a lowered threshold for the elicitation of shock-induced fighting behavior in septal animals one and one-half months after lesion placements (Allikmets \& Ditrikh, 1965). The present report describes the shock-induced fighting behavior of septal animals approximately three months postoperatively.

Subjects

Twenty-four rats of the Long-Evans strain obtained from a local supplier when they weighed between 225 and $250 \mathrm{~g}$ were used in the experiment. The rats were housed individually with free access to food and water at all times. Surgery was performed one week after the animals were introduced to the laboratory. Beginning 30 days postoperatively they were studied in an avoidance paradigm until one month before the present experiment which was conducted approximately 85 days postsurgery.

Apparafus

The experimental chamber ( $7 \times 7 \times 12$ in.) had a grid floor and three metal walls. The front wall was formed by .125 in. grids placed vertically on 0.5 in. centers, thus permitting unobstructed observation of animals in the chamber. The chamber was housed in a $4 \times 4 \times 7 \mathrm{ft}$ commercial sound attenuating enclosure (IAC Model No. 400A).

The grids and metal walls of the experimental chamber were connected to the output of a modified Grason-Stadler Shock Generator and Scrambler (Model No. E1064GS). The delivery of electric shock, as well as the duration and intensity of shock, were controlled automatically by conventional electromechanical switching and timing circuits.

Surgery

One group of animals $(\mathrm{N}=12)$ received large bilateral lesions in the septal region. Lesions were placed $7.4 \mathrm{~mm}$ anterior to the ear bars $.5 \mathrm{~mm}$ on both sides of the midline at a depth of $5.5 \mathrm{~mm}$ from the cortex. A monopolar electrode insulated except at the tip and powered by a rf lesion maker (Grass, Model LM3) was used to produce the brain lesions. The second group of animals $(\mathrm{N}=12)$ received sham operations in which the scalp and skull were opened and the dura insulted.

All lesions received histological verification.

Tesfing

Approximately 85 days postoperatively, the shockinduced fighting behavior (Ulrich \& Azrin, 1962) of pairs of rats, randomly formed within each group, was studied. The testing session consisted of presenting a series of electric shocks to each pair of rats while they were confined in the experimental chamber. A series of three shock intensities was employed. At each intensity a train of 10 shocks was presented; shock duration was $0.5 \mathrm{sec}$ and there was a $1.0 \mathrm{sec}$ interval between each shock in the train. Then, after a 15 sec interval of no shock, another train of 10 shocks was presented at a different intensity. Each of the three shock intensities was presented three times in this fashion, making a total of 90 shock trials ( 30 at each of three intensities). Shock intensities and order of presentation were as follows: $1.3,2.5$, $0.5,1.3,0.5,2.5,1.3,2.5$, and $0.5 \mathrm{~mA}$.

The behavior of the rats was scored on each shock trial according to the criteria previously described by Ulrich \& Azrin (1962) by an experienced observer who was not informed as to which group the tested pair belonged. A fighting response was scored when both animals were raised upon their hind legs and made physical contact with slapping or biting movements toward one another.

The behavior of each of the animals was also rated four times using the first five scales of the emotionality rating scale developed by King (1958). These ratings were initially obtained prior to operation, on the second day following lesion placements, again at approximately 30 days postoperatively and finally two days after the fighting tests.

Results

The mean emotionality ratings for the septal and sham groups are shown in Fig. 1. The groups did not differ prior to lesion but on the second day following 
operation the septal group rated significantly higher $(t=12.98$, df $=22, p<.001$ ). Unexpectedly (Yutzey, Meyer, \& Meyer, 1964) the groups also differed one month after lesion $(t=4.17, d f=22, p<.001)$. After repeated handling during avoidance learning and a time lapse of another two months, however, the septal and sham groups could not be distinguished in emotionality ratings.

Figure 2 presents the mean probability of fighting for each of the groups at the three shock intensities. An analysis of variance revealed that the difference in fighting between groups was statistically significant $(p<.001)$ as was the difference between intensities $(p<.001)$. In addition the groups by intensities interaction was significant $(p<.01)$.

Lesions were quite consistent in placement and extent, and were bilaterally symmetrical. They were, however, quite large, extending from the genu of the corpus callosum into the hippocampal commissure and destroying both the anterior limb of the fornix and the anterior commissure in addition to all septal structures.

\section{Diseussion}

Septal lesioned animals are clearly hyperemotional shortly after lesion in the standard rating of reactions to object presentations and handling. Although emotionality as measured by the rating scales subsides with the passage of time and/or stimulation, it is evident that another response, that of shock-induced fighting persists. Hence, fighting, like the changes in avoidance learning (Krieckhaus, Simmons, Thomas, \& Kenyon, 1964) in septal lesioned animals does not appear to correlate with the hyperemotionality as measured by the rating scales.

Studies by Lints (1965) have indicated that "jump" thresholds to electric shock are lowered in septal lesioned rats, and Urich \& Azrin (1962) have demon-

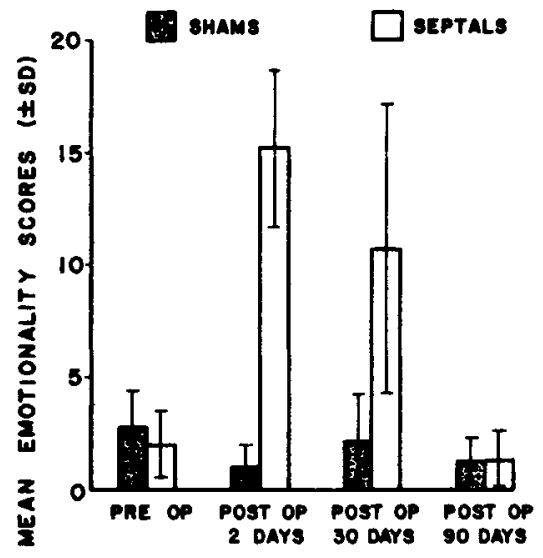

Fig. 1. Mean emotionality ratings of septal and sham groups on four occasions.

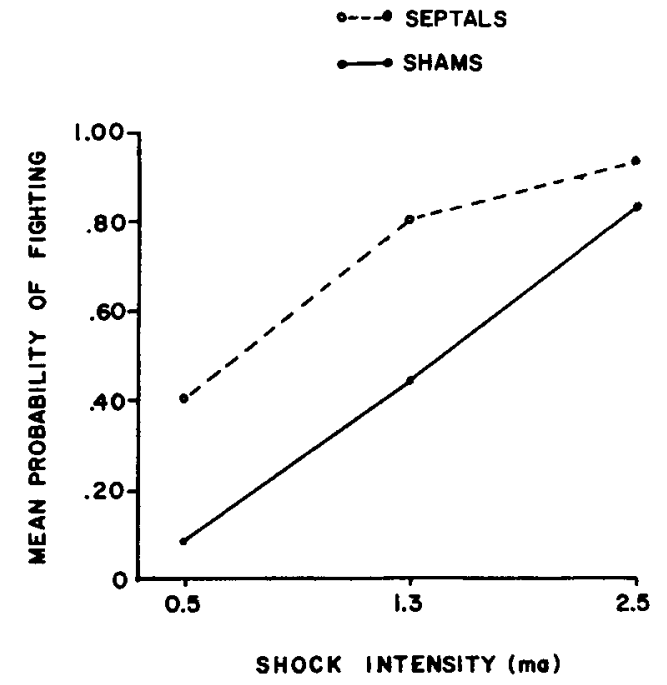

Fig. 2. Mean probability of fighting at each of three shock intensities for septal and sham groups.

strated the dependence of shock-incuced fighting upon shock levels. It is possible that the higher fighting levels shown by the septal lesioned animals at lower levels of shock, in the present experiment, are related to the threshold changes.

\section{References}

ALLIKMETS, L. Kh., \& DITRIKH, M. E. Effects of lesions of the limbic system on emotional reactions and conditioned reflexes in rats. Fed. Proc., 1965, 24, T 1003-T 1007.

BRADY, J. V., \& NAUTA, W. J. H. Subcortical mechanisms in emotional behavior: affective changes following septal forebrain lesions in the albino rats. J. comp. physiol. Psychol, 1953, 46, 339-346.

BRADY, J. V., \& NAUTA, W. J. H. Subcortical mechanisms in emotional behavior: the duration of affective changes following septal and habenular lesions in the albino rat. J. comp. physiol. Psychol, 1955, $48,412-420$.

KING, F. A. Effects of septal and amygdaloid lesions on emotional behavior and conditioned avoidance responses in the rat. $J$. nerv, ment. Dis, 1958, 126, 57-63.

KRIECKHAUS, E. E., SIMMONS, H. J., THOMAS, G. J., \& KENYON, J. Septal lesions enhance shock avoidance behavior in the rat. J. exp. Neurol, 1964, 9, 107-113.

LINTS, C. E. Changes in sensitivity to electric shock following central nervous system lesions in the rat. Unpublished doctoral dissertation, University of Chicago, 1965.

ULRICH, R., \& AZRIN, N. H. Reflexive fighting in response to avernive stimulation. J. exp. Anal. Behov., 1962, 5, 511-520.

YUTZEY, D. A., MEYER, P. M., \& MEYER, D. R. Emotionality changes following septal and neocortical ablation in rats. J. comp. physiol Psychol, 1964, 58, 463-465.

Notes

1. This research was supported by a grant from the National Institutes of Health, MH12732.

2. Supported by USPHS Research Training Grant in Biological Sciences, MH8304.

3. Research Career Development Award 5-K3-MH-19, 936-05. 